\title{
Improved drug loading via spray drying of a chalcone implant for local treatment of cutaneous leishmaniasis
}

\author{
Ariane J. Sousa-Batista ${ }^{a, b} \quad$, Natalia Arruda-Costa ${ }^{a}$, Bartira Rossi-Bergmann ${ }^{a}$ and Maria Inês Réb \\ anstitute of Biophysics Carlos Chagas Filho, Federal University of Rio de Janeiro, Rio de Janeiro, Brazil; ${ }^{b}$ Mines Albi, CNRS, Centre RAPSODEE, \\ Campus Jarlard, Université de Toulouse, Albi, France
}

\begin{abstract}
Current chemotherapy of cutaneous leishmaniasis $(\mathrm{CL})$, even the mildest forms, encompasses multiple and painful injections with toxic drugs that cause systemic adverse effects. Recently, we showed the promising use of poly(lactic-co-glycolic acid) (PLGA) microparticles loaded with an antileishmanial nitrosylated chalcone (CH8) for effective, safe, local, and single-dose treatment of CL. Here, we proposed to optimize the delivery system by increasing the $\mathrm{CH} 8$ loading in PLGA-microparticles using spray drying instead of emulsification-solvent evaporation. The effect of solvent composition and polymeric matrix changes on thermal properties, loading efficiency, particle size, morphology, and spatial drug distribution of the CH8-loaded microparticles was evaluated. The results showed that spray drying allowed a higher $\mathrm{CH} 8$ content $(18 \% \mathrm{w} / \mathrm{w})$, as contrasting with the previous solvent evaporation technique that maximally incorporated $7.8 \%$ of $\mathrm{CH} 8$. In vitro studies on 96-hour incubation with $L$. amazonensis-infected macrophages showed that entrapment in spray-dried PLGA microparticles rendered $\mathrm{CH} 8$ safer, preserved its antileishmanial activity, and did not affect its antioxidant properties.
\end{abstract}

\section{KEYWORDS}

Cutaneous leishmaniasis; leishmania; chemotherapy; chalcone; implant; polymeric microparticle; spray drying

\section{Introduction}

Leishmaniasis is a complex of disease caused by the infection with the protozoan parasites of the genus Leishmania that are transmitted by the bite of phlebotomine sandflies. Cutaneous leishmaniasis $(\mathrm{CL})$ is a dermal disorder witch cause high morbidity levels with a wide spectrum of clinical manifestations [1,2]. This disease is widespread in the world with approximately 0.7 to 1.2 million cases each year [3]. The first choice for $\mathrm{CL}$ treatment is the pentavalent antimonial drugs used since 1960 's. Pentamidine, amphotericin B, and paromomycin are considered as second choice drugs. However, all these available drugs can present hazardous side effects, emergence of drug-resistant, and variable efficacy in different geographic areas and Leishmania species $[1,4]$. The search for new drugs is urgently needed.

Different studies have been appointed chalcones and their derivatives as potential drug candidates for leishmaniasis treatment [5-9]. A new chalcone derivate, 3-nitro-2'-hydro-4',6'dimethoxychalcone $(\mathrm{CH} 8)$ synthesized and patented by our group has shown a promising activity against both promastigotes and intracellular amastigotes of Leishmania amazonensis. In a murine model of cutaneous leishmaniasis the $\mathrm{CH} 8$ displayed the same efficacy of the reference drug (Pentostan ${ }^{\circledR}$ ) in a dose 10 times lower [6].

To be successful, the treatment of $C L$ should be effective with low doses, local effect, and safe [10]. Intralesional antimonial administration has been explored and demonstrated a good effect, although this treatment is based on multiple injections that induce local pain and may cause side effects, like anaphylactic shock $[11,12]$. Topical treatments are an attractive alternative due to easier administration, lower side effects, and patient-compliance. Nonetheless most of the studies using topical formulations with paromomycin and amphotericin B presented low efficacy, due to their poor permeability through the skin, which need the use of permeation enhancers that promote an irritant effect and hamper their approval $[10,13-15]$.
Another interesting alternative for the local treatment of $\mathrm{CL}$ is the use of drug delivery systems. The polymeric implants systems have the advantages such as local action, reduced side effects, and improved patient compliance [16]. In leishmaniasis the implants based on microparticles can be up taken by macrophages, the main cell infected, which potentiate the drug effect [17]. Poly(lacticco-glycolic acid) (PLGA) implants are extensively applied in the clinical field due to their biocompatibility and biodegradability. Fifteen PLGA implants have been already approved by FDA from which, 11 are based on microparticles with applications in different diseases [18]. However, PLGA microparticle implants are poorly explored for the local treatment of $\mathrm{CL}$.

Recently our group produced a PLGA microparticle implant loaded with $7.8 \%$ of $\mathrm{CH} 8$ prepared by emulsion-solvent evaporation method. This formulation administrated in a single dose by intralesional route demonstrated the same efficacy than the free drug in three doses in mice infected with L. amazonensis [19]. However, the emulsion-solvent evaporation method has many process variables that can hinder the scale up. In addition, we believe that the increase of the drug load in the microparticle implant can improve its effectiveness in a single dose and reduce the treatment cost with lowers amounts of polymer per dose. The goal of this study was to increase the $\mathrm{CH} 8$ load in implant based on PLGA microparticles generated by spray drying as an alternative production method. The effect of some parameters such as the composition of the polymeric matrix and the type of solvent was studied in the present work.

\section{Materials and methods}

\section{Materials}

The following chemicals were used as received: PLGA 5004 (lactideglycolide molar ratio of 50:50, inherent viscosity of $0.41 \mathrm{dl} / \mathrm{g}$ ) 
was purchased from PURAC Biomaterials (Gorinchem, The Netherlands); polyvinylpyrrolidone K17 (PVP K17) (Kollidon_17 PF endotoxinfree, BASF AG, Ludwigshafen, Germany); dichloromethane (DCM - Sigma-Aldrich, St. Louis, MO); ethyl acetate (EA - Fluka); acetonitrile (Sigma-Aldrich); phosphoric acid (Fluka ${ }^{\text {TM }}$, Seelze, Germany). The synthetic Chalcone 3-nitro-2-hidroxi-4,6-dimetoxichalcona was prepared as previously shown and patented by our group $[6,20]$.

\section{Solubility parameter estimation}

The Hansen solubility parameter $(\delta)[21]$ was used to estimate the affinity between $\mathrm{CH} 8$ and PLGA, and PVP polymers and improved understanding of polymer effects in the final solid state of spraydried microparticles. The Hansen solubility parameter was calculated from the chemical structures of CH8, PLGA, and PVP using the Hoftyzer and Van Krevelen group contribution method [22] according to Equation (1):

$$
\delta=\left(\delta_{d}^{2}+\delta_{p}^{2}+\delta_{h}^{2}\right)^{1 / 2}
$$

where:

$$
\delta_{d}=\frac{\sum_{i} F d i}{V} ; \delta_{p}=\frac{\sqrt{\sum_{i} F^{2} p i}}{V} ; \text { and } \delta_{h}=\sqrt{\frac{\sum_{i} E h i}{V}}
$$

$V$ is the molar volume and Fdi, Fpi, and Ehi are the group contributions for the different types of interactions (dispersion forces, polar interactions, and hydrogen bonding, respectively), which are reported in the literature [21].

\section{Preparation of CH8-loaded polymeric microparticles}

CH8-loaded polymeric microparticles were prepared using a Buchi B-290 spray-dryer (Buchi Labortechnik AG, Flawil, Switzerland) equipped with Inert Loop B-295 and an integrated two-fluid $2 \mathrm{~mm}$ nozzle. Compressed nitrogen dispersed the liquid into fine droplets, which were consequently dried in the drying chamber and deposed in the cyclone. Drying conditions are given as follows for all prepared samples: aspirator $85 \%$; pump flow rate $360 \mathrm{ml} / \mathrm{h}$ and compressed nitrogen flow rate $500 \mathrm{l} / \mathrm{h}$. The inlet temperature was set to $49 \pm 1{ }^{\circ} \mathrm{C}$ and the resultant outlet temperature was $38 \pm 2{ }^{\circ} \mathrm{C}$. The experiments were made in duplicate.

The drug:polymer mass proportion (dry basis) was fixed at 1:5. PLGA alone or a mixture of PVP K17 and PLGA of 1:10 were used.
The feeding solution was prepared by dissolving $\mathrm{CH} 8$ in a $1.5 \%$ $(\mathrm{w} / \mathrm{v})$ solution of PLGA or PLGA/PVP K17 in dichloromethane or in a mixture of ethyl acetate in dichloromethane (1:2).

The individual polymers were also spray-dried from organic solutions. They were used for comparison purposes. All obtained powders were collected in glass containers and stored at $-20^{\circ} \mathrm{C}$ before further studies.

CH8-loaded polymeric microparticles were also produced by emulsification-solvent evaporation method. The preparation protocol was previously described by our group [19]. In our previous studies, a maximum $\mathrm{CH} 8$ loading of $7.8 \%$ was obtained by following this experimental protocol. The aim is to compare the performance of the CH8-loaded PLGA microparticles prepared by the two different processes, spray drying and emulsion-solvent evaporation.

Table 1 summarizes all studied formulations.

\section{Physico-chemical characterization of the CH8-loaded polymeric} microparticles

\section{Thermal analyses}

Thermal analyses were performed using a differential scanning calorimeter DSC Q2000 with the base module and modulate-DSC (TA Instruments, Leatherhead, UK). Samples were heated in non-hermetic aluminum pans at a rate of $5^{\circ} \mathrm{C} / \mathrm{min}$ from 15 to $200^{\circ} \mathrm{C}$ under nitrogen flow of $50 \mathrm{ml} / \mathrm{min}$ using an empty sealed pan as reference. DSC modulated technique (mDSC) was used to increase the resolution and the sensibility for weak transitions. In mDSC experiments, the samples were heated by a sinusoidal program of $2^{\circ} \mathrm{C} / \mathrm{min}$ from 20 to $150^{\circ} \mathrm{C}$, with the modulation period of $40 \mathrm{~s}$ and amplitude $0.8^{\circ} \mathrm{C}$.

\section{Drug loading}

Drug loading was determined by dissolving $2 \mathrm{mg}$ of PLGA or PLGA/PVP microparticles in $5 \mathrm{ml}$ of acetonitrile and analyzing the sample using high-performance liquid chromatography (HPLC). HPLC was performed on an Agilent chromatographic system (1100, Agilent), and a Grace C18 column $(250 \times 4.6 \mathrm{~mm} 5 \mu \mathrm{m}-$ 201TP54, Grace, Munich, Germany). Acetonitrile: phosphoric acid $0.01 \%$ in water $(80: 20, \mathrm{v} / \mathrm{v})$ was used as the mobile phase at a flow rate of $1.0 \mathrm{ml} / \mathrm{min}$. The ultraviolet detection was conducted at $337 \mathrm{~nm}$. Data was analyzed using the ChemStation software (Agilent, Palo Alto, CA). The calibration curve was

Table 1. Formulation parameters and thermal analysis (DSC) of the polymeric particles prepared by spray drying and

\begin{tabular}{|c|c|c|c|c|c|c|c|c|c|}
\hline \multirow[b]{3}{*}{ Code formulation } & \multirow[b]{3}{*}{ Polymer } & \multirow[b]{3}{*}{ Solvent } & \multicolumn{7}{|c|}{ Particles characteristics } \\
\hline & & & \multicolumn{4}{|c|}{ Size $(\mu \mathrm{m})$} & \multirow[b]{2}{*}{ Percentage $\mathrm{CH} 8$ loaded } & \multicolumn{2}{|c|}{ Thermal properties } \\
\hline & & & D10 & D50 & D90 & Span & & $\operatorname{Tg}\left({ }^{\circ} \mathrm{C}\right)$ & $\operatorname{Tm}$ onset $\left({ }^{\circ} \mathrm{C}\right)$ \\
\hline \multirow{2}{*}{\multicolumn{10}{|c|}{$\begin{array}{l}\text { Spray drying method } \\
\text { Blank (polymeric) particles }\end{array}$}} \\
\hline & & & & & & & & & \\
\hline PD & PLGA & DCM & 1.93 & 10.19 & 22.71 & 2.04 & - & 45.4 & - \\
\hline PDE & PLGA & DCM:EA & 1.46 & 6.21 & 16.63 & 2.44 & - & 46.3 & - \\
\hline VD & PVP & DCM & - & - & - & - & - & 145.5 & - \\
\hline PVD & PLGA:PVP & DCM & 2.13 & 5.30 & 14.47 & 2.33 & - & 45.9 & - \\
\hline PVDE & PLGA:PVP & DCM:EA & 1.88 & 4.35 & 12.18 & 2.37 & - & $\begin{array}{r}48.1 \\
154.0\end{array}$ & - \\
\hline \multicolumn{10}{|c|}{ CH8-loaded (polymeric) particles } \\
\hline $\mathrm{CH} 8 / \mathrm{PD}$ & PLGA & DCM & 2.69 & 12.34 & 25.82 & 1.87 & $18.34 \pm 0.02$ & 38.4 & 134.6 \\
\hline CH8/PVD & PLGA:PVP & DCM & 1.58 & 5.75 & 12.82 & 1.96 & $17.82 \pm 0.04$ & 40.9 & 136.0 \\
\hline $\mathrm{CH} 8 / \mathrm{PDE}$ & PLGA & DCM:EA & 1.53 & 8.40 & 17.99 & 1.96 & $18.10 \pm 0.01$ & 38.5 & 141.7 \\
\hline CH8/PVDE & PLGA:PVP & DCM:EA & 1.66 & 8.97 & 19.11 & 1.95 & $18.14 \pm 0.02$ & 38.5 & 139.2 \\
\hline \multicolumn{10}{|c|}{$\begin{array}{l}\text { Emulsion-solvent evaporation method } \\
\text { CH8-loaded (polymeric) particles }\end{array}$} \\
\hline $\mathrm{CH} 8 / \mathrm{PLGA}$ & PLGA & DCM & 0.60 & 5.49 & 13.40 & 2.30 & $7.84 \pm 1.50$ & 48.6 & 150.5 \\
\hline
\end{tabular}
by emulsion-solvent evaporation methods. 
$y=51.75 x+410.6(r=0.9992, n=3)$, which exhibited linearity over a concentration range of $50-300 \mu \mathrm{g} / \mathrm{ml}$ of $\mathrm{CH} 8$. The drug loading was calculated by the following Equation (2):

$$
\text { Drug loading }(\%)=\frac{\text { Weight of drug in spray }- \text { Dried microparticles }}{\text { Weight of spray }- \text { Dried microparticles }} \times 100 \%
$$

Size, morphology and drug distribution within the CH8-loaded polymeric microparticles

Particle size was determined by laser light scattering (Mastersizer 2000, Malvern, Worcestershire, UK) using a Fraunhofer diffraction model for the analysis of the raw data. The particles were dispersed in $0.5 \%(\mathrm{w} / \mathrm{w})$ Tween-20 solution and subsequently treated with ultrasound for $20 \mathrm{~s}(20 \mathrm{kHz}, 50 \mathrm{~W})$ [23]. Particle diameter was expressed as the values of D90, D50, and D10, where 90th, 50th, and 10th percent of the population lies below this value. Polydispersity was given by span index, calculated by (D90 - D10)/D50.

The morphology and the surface structure were assayed by field emission gun scanning electron microscopy (FEG-SEM) using Philips XL30 ESEM-FEG instrument (Philips, Eindhoven, Netherlands) operating at an acceleration voltage of $20 \mathrm{kV}$ under nitrogen atmosphere. The microparticles were fixed on an aluminum stub using double-sided carbon tape and was coated by sputtering with gold for four minutes at 18,000 mA using a Polaron SC7640 (Quorom Technology, England).

The drug distribution in the spray-dried microparticles was mapped by Raman microscopy (Alpha $300 \mathrm{R}$ Raman-AFM spectrophotometer, WITEC GmbH, Germany). The spectra were obtained at room temperature and 50X magnification using a confocal laser wavelength of $532 \mathrm{~nm}$ (Nd:YAG laser) and ultrahigh-throughput (UHTS 300) spectroscopy system with a CCD charge-coupled device (CCD) as detector. Each spectral scan was collected for $0.5 \mathrm{~s}$ of integration using ten accumulations and each sample was analyzed three times.

\section{Biological evaluation}

\section{Antileishmanial activity}

The antileishmanial activity of $\mathrm{CH} 8$-loaded polymeric microparticles was evaluated against intracellular amastigote of L. amazonensis (Josefa strain). Adherent mouse peritoneal macrophages $\left(5 \times 10^{5}\right.$ cells) were plated on coverslips and infected with $5 \times 10^{6}$ promastigotes for $4 \mathrm{~h}$ at $34^{\circ} \mathrm{C}$, after which non-internalized parasites were removed with warm phosphate buffered saline (PBS). Then, to allow for intracellular amastigote growth, the cells were cultured for a further $24 \mathrm{~h}$ at $37^{\circ} \mathrm{C}$ in Roswell Park Memorial Institute medium (RPMI) supplemented with 5\% heat-inactivated fetal bovine serum (HIFBS, Cultilab, Brazil).

Next, the infected macrophages were treated for $96 \mathrm{~h}$ in triplicates with a range of concentrations $(0.5,5$, and $50 \mu \mathrm{g} / \mathrm{ml})$ of free $\mathrm{CH} 8$ or $\mathrm{CH} 8$ encapsulated in microparticles produced by spray drying $(\mathrm{CH} 8 /$ PDE and CH8/PVDE) or emulsification-solvent evaporation ( $\mathrm{CH} 8$ / PLGA). At the end of treatment time, the cell monolayers were stained with Giemsa and the numbers of amastigotes in total 200 macrophages per coverslip were counted in Neubauer chambers. The results were expressed both as amastigotes per 100 macrophages and $\mathrm{IC}_{50}$ (drug concentration that inhibited parasite growth by $50 \%$ ).

\section{Anti-macrophage cytotoxicity}

The 'resazurin reduction test' is a very simple and versatile way to measure cell cytotoxicity. This method is based on the enzymatic reduction of resazurin sodium salt (blue and nonfluorescent) to resorufin (pink and highly fluorescent) by metabolically active cells [24]. For evaluation of the anti-macrophage cytotoxicity, macrophages were infected and treated for $96 \mathrm{~h}$ with $\mathrm{CH} 8$ encapsulated or not, as described above for antileishmanial activity. Then, $10 \%(\mathrm{v} / \mathrm{v})$ of resazurin solution $(0.125 \mathrm{mg} / \mathrm{ml}$;Sigma-Aldrich) was added in the medium and cells were cultured for additional four hours at $37^{\circ} \mathrm{C}$. Following incubation, the fluorescence was measured at 555/585 nm (Bio-Tek Powerwave XS, Winooski, VT). The results were reported as the percentage of viable cells normalized to untreated cells. The $50 \%$ cytotoxic concentration $\left(\mathrm{CC}_{50}\right)$ values were determined by logarithmic regression analysis.

\section{Nitric oxide (NO) production}

The NO induction by microparticles was assessed in both uninfected and L. amazonensis-infected macrophages, as described for antileishmanial activity. After $24 \mathrm{~h}$ of infection, the cells were treated for additionally $96 \mathrm{~h}$ with $\mathrm{CH} 8$ encapsulated or not $(50 \mu \mathrm{g} / \mathrm{ml})$ or equivalent amounts of blank microparticles. As controls untreated cells and $1 \mu \mathrm{g} / \mathrm{ml}$ of lipopolysaccharide (LPS Escherichia coli, Sigma-Aldrich)-treated cells were used. The stable sodium nitrite $\left(\mathrm{NaNO}_{2}\right)$ product was measured in the culture supernatants at $570 \mathrm{~nm}$ (BIO-TEK, Powerwave XS) by Griess colorimetric method and $\mathrm{NaNO}_{2}$ standard curve [25].

\section{Statistical analysis}

Unpaired t test with Welch's correction was performed to demonstrate statistical differences $(p<.05)$ between two groups. IC $C_{50}$ values were calculated from a curve of sigmoidal dose-response. All analysis were conducted using GraphPad Prism 5 software (GraphPad Software, La Jolla, CA).

\section{Results and discussion}

\section{Physicochemical characterization of CH8-loaded polymeric} microparticles

\section{Thermal properties}

All heating curves obtained from DSC analyses are grouped in Figure 1, including the heating curve of a physical mixture between $\mathrm{CH} 8$ and PLGA in a mass proportion of 1:2. The thermal profile of unprocessed $\mathrm{CH} 8$ crystals shows a distinct melting endotherm ( $\left(\mathrm{m}_{\text {onset }}\right)$ at $166.3^{\circ} \mathrm{C}$ with a $\Delta \mathrm{H}_{\mathrm{m}}$ of $89.21 \mathrm{~J} / \mathrm{g}$. Amorphous PLGA has a glass temperature $(\mathrm{Tg})$ in the range of $45.4-46.3^{\circ} \mathrm{C}$ (PD and PDE, respectively), whereas spray-dried PVP has a $\mathrm{Tg}$ of $145.5^{\circ} \mathrm{C}$ (VD).

The fast solvent evaporation of solvents from organic solutions containing two dissolved constituents, drug and polymer, in most cases leads to the formation of amorphous solids dispersions during spray drying [26]. An amorphous solid dispersion constituted of $\mathrm{CH} 8$ and PLGA or PLGA/PVP could be theoretically expected from the analysis of their molecular structure and solubility parameters $(\delta)$. The solubility parameters $(\delta)$ for $\mathrm{CH} 8$ from its molecular division in groups was calculated to be $21.9 \mathrm{MPa}^{1 / 2}$. The $\delta$ t calculated values for PLGA $\left(24.36 \mathrm{MPa}^{1 / 2}\right)$ and PVP $\left(23.36 \mathrm{MPa}^{1 / 2}\right)$ are close to data found in the literature $[21,27,28]$. It is generally believed that favorable interactions and a uniform phase will result when the difference in $\delta$ t values between two components $(\Delta \delta \mathrm{t})$ is less than $7 \mathrm{MPa}^{1 / 2}$, while unfavorable interactions and phase separation will result when $\Delta \delta \mathrm{t}$ $>10 \mathrm{MPa}^{1 / 2}[29]$. In the present case, $\Delta \delta$ t between $\mathrm{CH} 8$ and all polymers used is lower than $3 \mathrm{MPa}^{1 / 2}$ and $\mathrm{CH} 8$ is likely to be miscible with these polymers in the spray-dried microparticles.

However, despite the favorable outcome in the $\Delta \delta \mathrm{t}$, the spraydried $\mathrm{CH} 8$-loaded polymeric microparticles are not constituted by a homogeneous mixture of amorphous components. In fact, from the DSC results (Table 1), all CH8 loaded-polymer particles present 
a clear $T g$ corresponding to the $T g$ of the polymers and in addition a melting endotherm near to the melting point $(T \mathrm{~m})$ of the $\mathrm{CH} 8$ crystalline form. The presence of the polymers in the spraydried microparticles led to a depression in the melting point of the drug in the binary mixtures. This finding could be indicative of mixing between two components, as already found and discussed in the literature for other binary mixtures of drug and polymer [30]. In theory, melting of a crystal occurs at the temperature when the chemical potential of the crystal is equal to the chemical potential of the melt. Addition of an amorphous polymer to the crystal (if miscible) reduce the chemical potential of the crystalline material leading to the reduction of its melting temperature [31].

DCM alone and a mixture of DCM:EA (1:2) were used as solvents for drug and polymers. The influence of the initial solvent composition on the thermal properties of the spray-dried microparticles can be observed with a lower depression of $T \mathrm{~m}$ when DCM was used as solvent (Table 1). PLGA is less soluble in EA than in DCM, probably the lower solubility of PLGA in the mixtures DCM:EA led to a more rapid precipitation of the polymer interfering in drug-polymer interaction.

Another investigation carried out in this study was the introduction of PVP $(10 \% \mathrm{w} / \mathrm{w})$ in the polymeric matrix. PVP is a biocompatible and hydrophilic polymer, capable of promoting the formation of solid amorphous dispersions by forming electrostatic interactions with several drugs [32]. Irrelevant differences were observed in the Tm of the drug in spray-dried PLGA microparticles containing PVP in the polymeric matrix compared to the $\mathrm{CH} 8$ loaded PLGA microparticles without PVP (Table 1).

\section{Drug loading efficiency}

The spray-dried $\mathrm{CH} 8$-loaded polymeric microparticles covered an actual drug loading range of 17.8 to $18.3 \% \mathrm{w} / \mathrm{w}$, compared to $7.8 \% \mathrm{w} / \mathrm{w}$ for the microparticles obtained by emulsion-solvent evaporation (Table 1). The changes in the polymeric matrix or solvent composition did not significantly modify the high drug loading efficiency (>96\%) for the spray-dried microparticles.

\section{Particle size, morphology, and spatial drug distribution}

Despite of all modifications in the spray-dried formulations, the particle size ranged from 1.5 (D10) to $26 \mu \mathrm{m}$ (D90; Table 1), in a very close way. In comparison, CH8-loaded PLGA microparticles prepared by emulsion and solvent evaporation showed a smaller size range (from 0.6 (D10) to $13.4 \mu \mathrm{m}$ (D90). This variety in the microparticle distribution size is interesting because the microparticles below $10 \mu \mathrm{m}$ can be efficiently uptake by macrophages [33], the main cell infected in leishmaniasis, while the largest were desired to obtain injectable microparticles for depot applications [34,35].

All particles were analyzed by FEG-SEM and showed a similar topography. Figure 2 depicts a representative picture of PLGA microparticles loaded with $\mathrm{CH} 8$ showing that they are spherical and
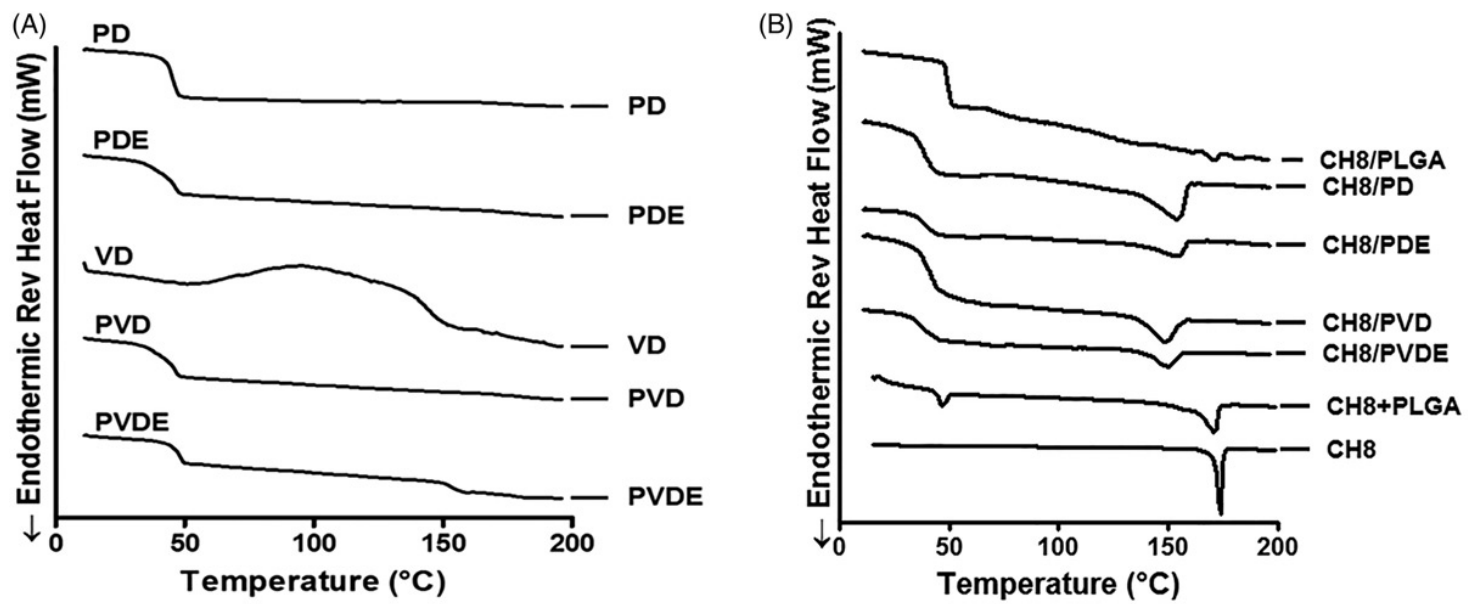

Figure 1. DSC thermograms. (A) Blank microparticles (PVDE; PVD; VD; PDE, and PD); (B) CH8's microparticles produced by spray drying (CH8/PVDE; CH8/PDE; CH8/PVD, and $\mathrm{CH} 8 / \mathrm{PD}$ ) and by emulsion-solvent evaporation (CH8/PLGA) methods, unprocessed $\mathrm{CH} 8$ crystals (CH8) and physical mixture between $\mathrm{CH} 8$ and PLGA was in a mass proportion of $1: 2(\mathrm{CH} 8+\mathrm{PLGA})$.


Figure 2. SEM micrograph of PLGA microparticles with $\mathrm{CH}$ 8. (A) Intact particles; (B) Particles rubbed out by friction, showing the inside with crystal shapped CH8 chalcone (white arrows). 
have a relatively smooth surface (Figure $2(A)$ ). The intentional wear in the surface of the particles revealed an interior probably rich in drug crystals (Figure 2(B)). To confirm this statement, the spatial distribution of components inside the microparticles was evaluated by RAMAN microscopy mapping. For this, surface $(20 \times 20 \mu \mathrm{m})$ and deep spectra $(9 \times 9 \mu \mathrm{m})$ have been taken for accuracy.

RAMAN microcopy has been used to study the distribution of drugs in drug delivery systems without the need to mark the molecule [36]. Our results confirmed that $\mathrm{CH} 8$ loaded-polymeric microparticles have an outer phase composed of a mixture of drug and polymer (peaks around $1600 \mathrm{~cm}^{-1}$ of $\mathrm{CH} 8$ and peaks between 2800 and $3200 \mathrm{~cm}^{-1}$ of PLGA or PLGA/PVP) and an inner phase where the drug predominates (Figure 3). All particles studied showed the same polymer and drug distributions, although it was not possible to differentiate the PLGA and PVP spatial distributions, because of their similar spectra with mean peaks between 2800 and $3200 \mathrm{~cm}^{-1}$.

No changes were observed in the microparticles characteristics, even though the physical composition of the microparticles were altered. The microparticles produced with DCM:EA as solvent phase was chosen to continue the in vitro experiments, because they were produced with a lower ratio of DCM in the feed solution, creating a more sustainable method.

\section{Biological evaluation of the CH8-loaded PLGA microparticles}

\section{Antileishmanial activity}

All $\mathrm{CH} 8$ formulations were active against intracellular amastigotes of $L$. amazonensis. As demonstrated before, encapsulation of $\mathrm{CH} 8$

(A)

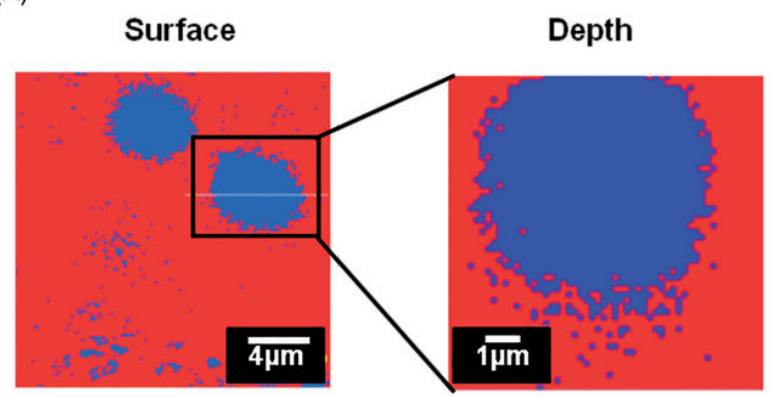

(C)

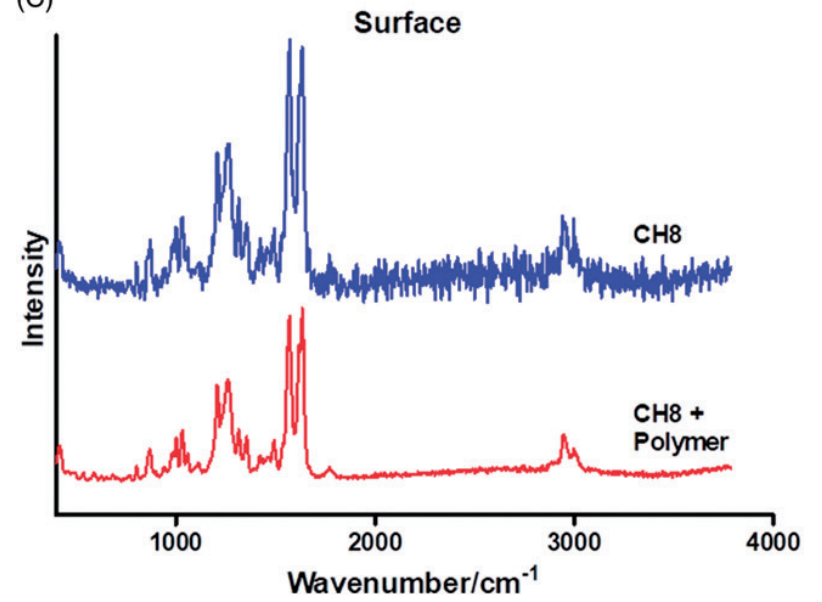

in PLGA microparticles preserved the $\mathrm{CH} 8$ antileishmanial activity [19] and the addition of PVP in the polymeric matrix did not modify this effect. Nonetheless, encapsulation of $\mathrm{CH} 8$ into microparticles slightly increased its $\mathrm{IC}_{50}$ from $0.4 \mu \mathrm{g} / \mathrm{ml}$ (free $\mathrm{CH} 8$ ) to $0.9-1.9 \mu \mathrm{g} / \mathrm{ml}$ ( $\mathrm{CH} 8$ loaded polymeric microparticles), as shown in Figure 4. That is probably due to the slow drug release from microparticles in the intracellular milieu. The process that led to higher $\mathrm{CH} 8 / \mathrm{PLGA}$ activity was emulsification-solvent evaporation $\left(\mathrm{IC}_{50}=0.9 \mu \mathrm{g} / \mathrm{ml}\right)$, as compared with spray drying $(\mathrm{CH} 8 /$ PVDE: $1.8 \mu \mathrm{g} / \mathrm{mL}$ and CH8/PDE: $1.9 \mu \mathrm{g} / \mathrm{ml}$ ). Since CH8/PLGA

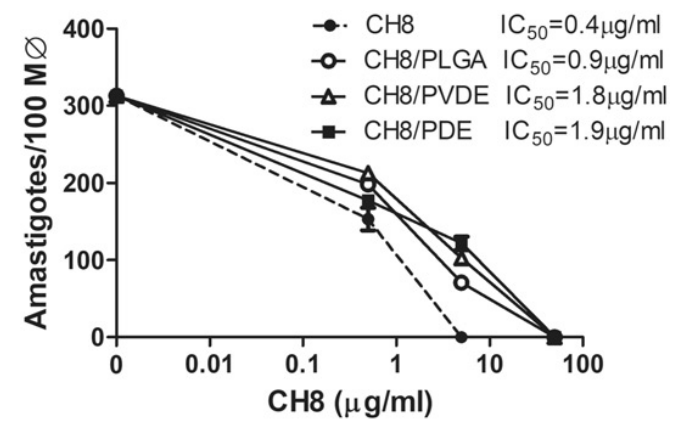

Figure 4. Antiamastigote activity. L. amazonensis-infected macrophages were treated with free or encapsulated $\mathrm{CH} 8(0 ; 0.5 ; 5$, and $50 \mu \mathrm{g} / \mathrm{ml})$ or left untreated for $96 \mathrm{~h}$ at $37^{\circ} \mathrm{C}$. The intracellular amastigote loads, in total 100 macrophages/ coverslip, were counted in Giemsa-stained cells. The half maximal inhibitory concentration $\left(\mathrm{IC}_{50}\right)$ values were determined by logarithmic regression analysis. Means \pm SD $(n=3)$.

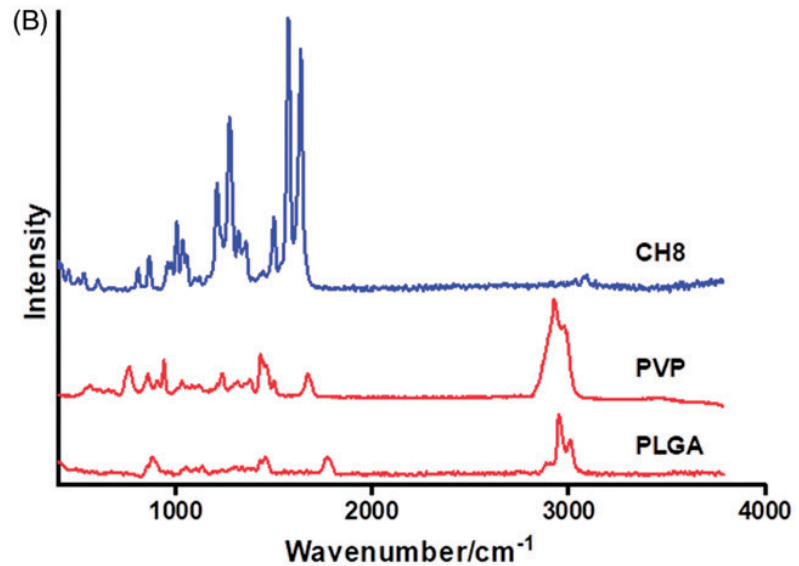

(D)

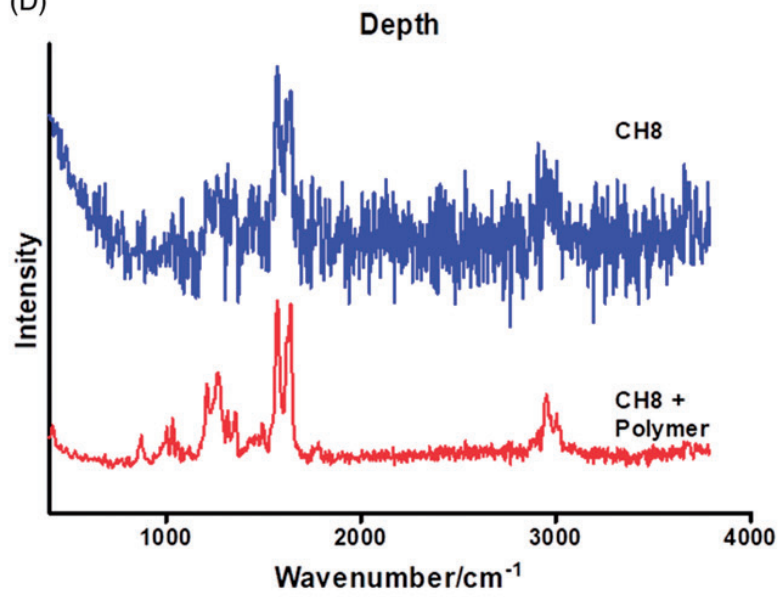

Figure 3. Representative Raman mapping of the microparticles with peaks of CH8 (peaks around $1600 \mathrm{~cm}^{-1}$ ) and PLGA (peaks between 2800 and $3200 \mathrm{~cm}^{-1}$ ) in the surface $(20 \times 20 \mu \mathrm{m})$ and deep spectra $(9 \times 9 \mu \mathrm{m})$. 


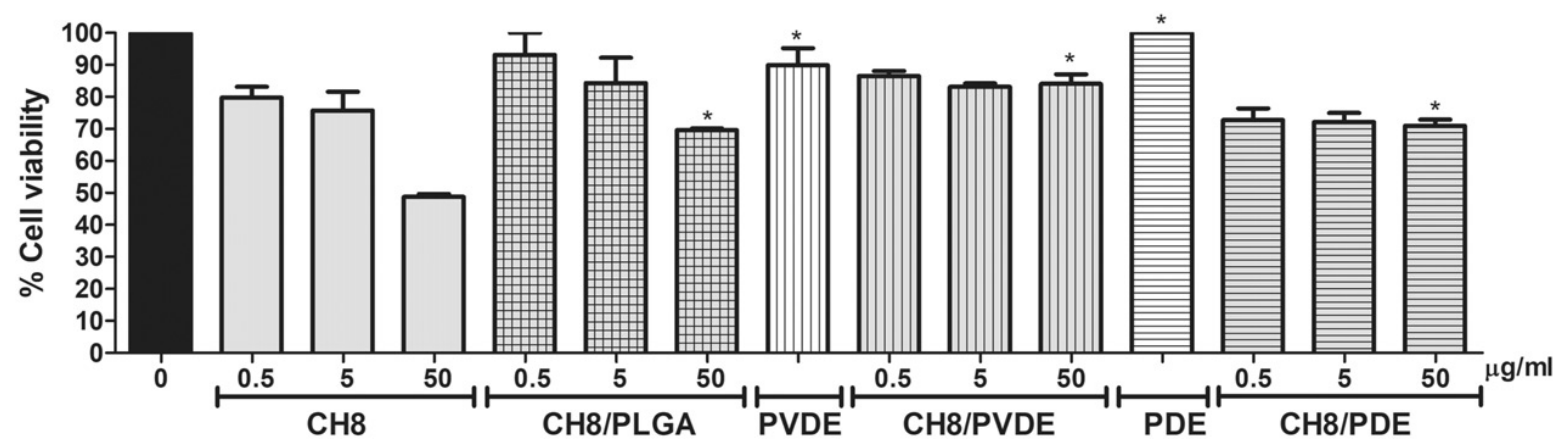

Figure 5. Microparticles cytotoxicity. L. amazonensis-infected macrophages were treated for $96 \mathrm{~h}$ with free or encapsulated $\mathrm{CH} 8(0 ; 0.5 ; 5$, and $50 \mu \mathrm{g} / \mathrm{ml})$ or blank microparticles $\left(50 \mu \mathrm{g} / \mathrm{ml}\right.$ of encapsulated $\mathrm{CH} 8$-equivalent doses), or left untreated. Following treatment, the cell viability was evaluated after cell incubation for $4 \mathrm{~h}$ at $37^{\circ} \mathrm{C}$ with $10 \%$ of resazurin $(0.125 \mathrm{mg} / \mathrm{ml})$ and fluorescence measurement at $555 / 585 \mathrm{~nm}$. The result was plotted as percentage cell viability considering untreated as $100 \%$ of cell viability. Untreated fluorescence units $=2.07 \times 10^{7} \pm 1.58 \times 10^{5}$. Mean $\pm \mathrm{SD}(n=3)$. ${ }^{*} p<.05$ vs. CH8 group in the same concentration.

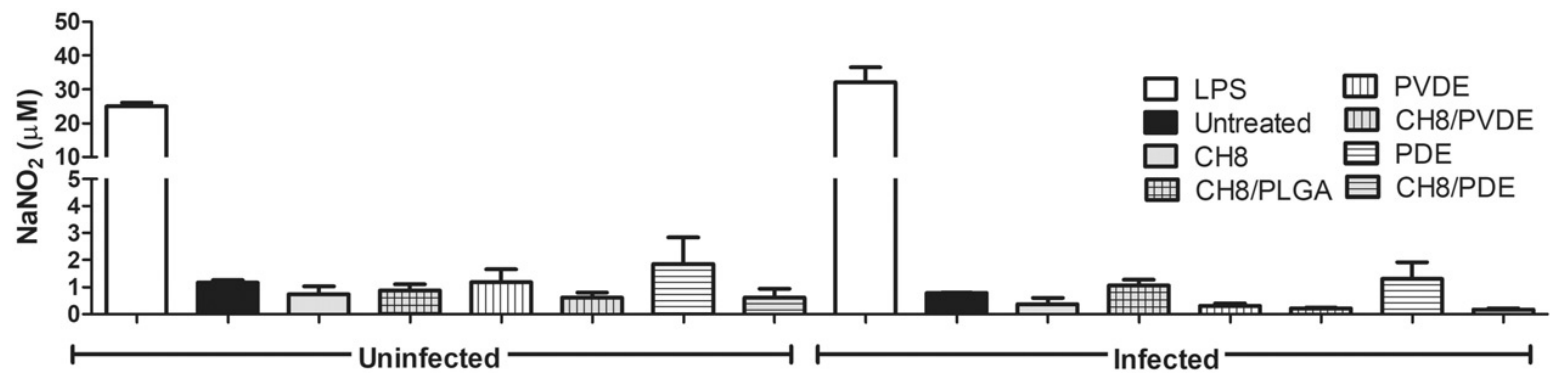

Figure 6. NO production. L. amazonensis-infected and uninfected peritoneal macrophages were treated with blank microparticles, encapsulated, or free CH8 $(50 \mu \mathrm{g}$ $\mathrm{CH} 8 / \mathrm{ml}$ and equivalent amounts of particle), or left untreated. Treatment with LPS $(1 \mu \mathrm{g} / \mathrm{ml})$ was used as a positive control. After $96 \mathrm{~h}$ at $37^{\circ} \mathrm{C}$, culture supernatants were collected to assess the production of NO by colorimetric assay using Griess reagent. Mean \pm SD $(n=3)$.

microparticles can be efficiently internalized by macrophages [19], the higher CH8/PLGA activity may be related to its higher uptake by macrophages due to the smaller size.

\section{Anti-macrophage cytotoxicity}

PLGA microparticles are widely used in different FDA-approved products, supporting their safety [18,37]. CH8 safety and antileishmanial activity have also been described [6]. However, in this work, the safety of their formulation was evaluated. Despite of the high antileishmanial activity of $\mathrm{CH} 8$, cytotoxicity was observed in higher concentrations of these drug [19]. Our in vitro studies on 96-hour incubation with L. amazonensis-infected macrophages showed that all CH8-loaded microparticles tested (CH8/PLGA, CH8/ $\mathrm{PDE}$, and $\mathrm{CH} 8 / \mathrm{PVDE}$ ) displayed higher safety than free $\mathrm{CH} 8$ $\left(\mathrm{CC}_{50}>50\right.$ and $36.8 \mu \mathrm{g} / \mathrm{ml}$, respectively; Figure 5). The slight decrease in cell viability observed in CH8-loaded polymeric microparticles may be a drug effect, since blank microparticles (with or without PVP) did not modify cell viability.

\section{NO production}

Macrophage microbicidal mechanisms such as reactive oxygen species (ROS) and NO production play an important role in the control of Leishmania infection [38,39]. It is also known that NO induction directly correlates with decreased parasite loads in patients with cutaneous leishmaniasis [40]. Additionally, endocytosis itself may induce physical changes in the plasma membrane, which culminates with the activation of nitric oxide synthase and NO generation [17]. Then, to verify if the microparticle uptake interfered with oxidative mechanisms, NO production was evaluated in infected and uninfected macrophages following addition of free or encapsulated $\mathrm{CH} 8$ to cells. However, no NO production was induced (Figure 6) and was also seen to be compatible with the antioxidant [41] and anti-inflammatory properties of chalcones, even with a decrease in NO production $[42,43]$. In all, these results show that PLGA microparticles do not revert the antioxidative mechanisms of $\mathrm{CH} 8$ in macrophages. So, the $\mathrm{CH} 8$-microparticles antileishmanial activity was due to the direct action of the intracellularly released $\mathrm{CH} 8$ and was not to due to the macrophage activation, compatible with the direct action of $\mathrm{CH} 8$ in the Leishmania mitochondria $[5,8]$.

\section{Conclusion}

Alternative treatments of $\mathrm{CL}$ using safer drugs and reduced doses are urgently need. Polymeric implants emerge as an attractive strategy to solve this problem. However, to the best of our knowledge, this is the first attempt to develop chalcone implant based on spray-dried PLGA microparticles. In the current work, spray drying allowed the efficiently production of $\mathrm{CH} 8$ loaded-PLGA microparticles with an increase around $125 \%$ in the $\mathrm{CH} 8$ chalcone content in relation to the microparticles obtained previously by an emulsionsolvent evaporation process. Besides, in our in vitro studies, the CH8-microparticles showed to be safe and active against Leishmania amazonensis amastigotes. In future studies, we propose to evaluate in vivo the efficacy and safety of encapsulated $\mathrm{CH} 8$ in experimental models of cutaneous leishmaniasis.

\section{Acknowledgements}

The authors acknowledge to S. Delconfetto, C. Rolland, L. Haurie, and P. Accart from Rapsodee Centre for DSC, SEM, Raman and particle size measurements help and analyses, respectively. The first author also acknowledges CNPq (Brazilian Research Council for Scientific and 
Technological Development) and CAPES (Brazilian Federal Agency for Support and Evaluation of Graduate Education within the Ministry of Education of Brazil) for providing PhD Research Fellowship.

\section{Disclosure statement}

No potential conflict of interest was reported by the authors.

\section{Funding}

This work was supported by funding from Brazilian Research Council for Scientific and Technological Development (CNPq) [grant number 402787/2013-7].

\section{References}

[1] Iqbal $H$, Ishfaq $M$, Wahab $A$, et al. Therapeutic modalities to combat leishmaniasis, a review. Asian Pacific J Trop Dis. 2016;6:1-5.

[2] Kevric I, Cappel MA, Keeling JH. New world and old world leishmania infections: a practical review. Dermatol Clin. 2015;33:579-593.

[3] Alvar J, Vélez ID, Bern C, et al. Leishmaniasis worldwide and global estimates of its incidence. PLoS One. 2012;7:e35671.

[4] Sundar S, Chakravarty J. An update on pharmacotherapy for leishmaniasis. Expert Opin Pharmacother. 2014;16:1-16.

[5] Torres-Santos EC, Moreira DL, Kaplan MAC, et al. Selective effect of 2',6'-dihydroxy-4'-methoxychalcone isolated from Piper aduncum on Leishmania amazonensis. Antimicrob Agents Chemother. 1999;43:1234-1241.

[6] Boeck P, Bandeira Falcão CA, Leal PC, et al. Synthesis of chalcone analogues with increased antileishmanial activity. Bioorganic Med Chem. 2006;14:1538-1545.

[7] Chen M, Christensen SB, Theander TG, et al. Antileishmanial activity of licochalcone $A$ in mice infected with Leishmania major and in hamsters infected with Leishmania donovani. Antimicrob Agents Chemother. 1994;38:1339-1344.

[8] Zhai L, Chen M, Blom J, et al. The antileishmanial activity of novel oxygenated chalcones and their mechanism of action. J Antimicrob Chemother. 1999;43:793-803.

[9] Mattos CB, Argenta DF, Melchiades G, et al. Nanoemulsions containing a synthetic chalcone as an alternative for treating cutaneous leshmaniasis: optimization using a full factorial design. Int J Nanomedicine. 2015;10:5529-5542.

[10] DNDi. InfoLEISH: Boletim informativo da redeLEISH [Internet]. 2016. Available from: https://www.dndi.org/wpcontent/uploads/2016/06/DNDi_Infoleish_Newsletter_1_ PORTUGUESE_160510.pdf

[11] Oliveira-Neto MP, Schubach A, Mattos $M$, et al. Intralesional therapy of American cutaneous leishmaniasis with pentavalent antimony in Rio de Janeiro, Brazil - an area of Leishmania (V.) braziliensis transmission. Int J Dermatol. 1997;36:463-468.

[12] Esfandiarpour I, Farajzadeh S, Rahnama Z, et al. Adverse effects of intralesional meglumine antimoniate and its influence on clinical laboratory parameters in the treatment of cutaneous leishmaniasis. Int J Dermatol. 2012;51: $1221-1225$.
[13] Ben Salah A, Ben Messaoud N, Guedri E, et al. Topical paromomycin with or without gentamicin for cutaneous leishmaniasis. N Engl J Med. 2013;368:524-532.

[14] Garnier T, Croft SL. Topical treatment for cutaneous leishmaniasis. Curr Opin Investig Drugs. 2002;3:538-544.

[15] Bocxlaer K, Van Yardley V, Murdan S, et al. Drug permeation and barrier damage in Leishmania-infected mouse skin. J Antimicrob Chemother. 2016;71:1578-1585.

[16] Ahmed TA, Ibrahim HM, Samy AM, et al. Biodegradable injectable in situ implants and microparticles for sustained release of montelukast: in vitro release, pharmacokinetics, and stability. AAPS PharmSciTech. 2014;15:772-780.

[17] Nicolete R, Santos DF, Dos, Faccioli LH. The uptake of PLGA micro or nanoparticles by macrophages provokes distinct in vitro inflammatory response. Int Immunopharmacol. 2011; 11:1557-1563.

[18] Wang Y, Qu W, Choi SH. FDA's regulatory science program for generic PLA/PLGA - based drug products. Am Pharm Rev. 2016;19:5-9.

[19] Sousa-Batista AJ, Pacienza-Lima W, Arruda-Costa N, et al. Depot subcutaneous injection with chalcone $\mathrm{CH} 8$-loaded poly(lactic-co-glycolic acid) microspheres as a single-dose treatment of cutaneous leishmaniasis. Antimicrob Agents Chemother. 2018;62:e01822-17.

[20] Rossi-Bergmann B, Torres-Santos EC, Yunes RA, et al. Síntese e uso de chalconas para tratamento de doenças parasitárias [Synthesis and use of chalcones for the treatment of parasitic diseases]. PI0204079-4. [Internet]. 2004. Available from: https://gru.inpi.gov.br/pePI/servlet/Patente ServletController?Action $=$ detail $\&$ CodPedido $=615480 \&$ Search Parameter=PI0204079-4\%20\%20\%20\%20\%20\%20\&Resumo= \&Titulo $=$

[21] Hansen MC, editor. Hansen solubility parameters: a user's handbook. 2nd ed. Flórida: CRC Press; 2007.

[22] van Krevelen DW. Properties of polymers: their correlation with chemical structure: their numerical estimation and prediction from additive group contributions. 4th ed. Oxford (UK): Elsevier; 2009.

[23] Schafroth N, Arpagaus C, Jadhav UY, et al. Nano and microparticle engineering of water insoluble drugs using a novel spray-drying process. Colloids Surfaces B Biointerfaces. 2012;90:8-15.

[24] O'Brien J, Wilson I, Orton T, et al. Investigation of the Alamar Blue (resazurin) fluorescent dye for the assessment of mammalian cell cytotoxicity. Eur J Biochem. 2000; 267:5421-5426.

[25] Bredt DS, Snyder SH. Nitric oxide: a physiologic messenger molecule. Annu Rev Biochem. 1994;63:175-195.

[26] Lavra ZMM, Pereira de Santana D, Ré MI. Solubility and dissolution performances of spray-dried solid dispersion of Efavirenz in Soluplus. Drug Dev Ind Pharm. 2016;9045:1-13.

[27] Madsen CG, Skov A, Jørgensen L, et al. Effect of mixed solvents on polymer conformation - correlation between the hildebrand/hansen solubility parameters and the intrinsic viscosity of polymer solutions. Annu Trans Nord Rheol Soc. 2013;21:347-352.

[28] Schenderlein S, Lück M, Müller BW. Partial solubility parameters of poly(D,L-lactide-co-glycolide). Int J Pharm. 2004;286: 19-26.

[29] Greenhalgh DJ, Williams AC, Timmins $P$, et al. Solubility parameters as predictors of miscibility in solid dispersions. J Pharm Sci. 1999;88:1182-1190. 
[30] Baird JA, Taylor LS. Evaluation of amorphous solid dispersion properties using thermal analysis techniques. Adv Drug Deliv Rev. 2012;64:396-421.

[31] Marsac PJ, Shamblin SL, Taylor LS. Theoretical and practical approaches for prediction of drug-polymer miscibility and solubility. Pharm Res. 2006;23:2417-2426.

[32] Folttmann H, Quadir A. Polyvinylpyrrolidone (PVP) - one of the most widely used excipients in pharmaceuticals: an Overview. Drug Deliv Technol. 2008;8:22-27.

[33] Champion J, Walker A, Mitragotri S. Role of particle size in phagocytosis of polymeric microspheres. Pharm Res. 2008; 25:1815-1821.

[34] Gaumet M, Vargas A, Gurny R, et al. Nanoparticles for drug delivery: the need for precision in reporting particle size parameters. Eur J Pharm Biopharm. 2008;69:1-9.

[35] Siepmann J, Siegel RA, Rathbone MJ, editors. Fundamentals and applications of controlled release drug delivery. New York: CRS; Springer; 2012.

[36] Paudel A, Raijada D, Rantanen J. Raman spectroscopy in pharmaceutical product design. Adv Drug Deliv Rev. 2015;89:3-20.

[37] Wan F, Yang M. Design of PLGA-based depot delivery systems for biopharmaceuticals prepared by spray drying. Int $J$ Pharm. 2015;498:82-95.
[38] Diefenbach a, Schindler H, Donhauser N, et al. Type 1 interferon (IFNalpha/beta) and type 2 nitric oxide synthase regulate the innate immune response to a protozoan parasite. Immunity. 1998;8:77-87.

[39] Murray HW, Nathan CF. Macrophage microbicidal mechanisms in vivo: reactive nitrogen versus oxygen intermediates in the killing of intracellular visceral Leishmania donovani. J Exp Med. 1999;189:741-746.

[40] Qadoumi M, Becker I, Donhauser N, et al. Expression of inducible nitric oxide synthase in skin lesions of patients with American cutaneous leishmaniasis. Infect Immun. 2002;70:4638-4642.

[41] Sivakumar PM, Prabhakar PK, Doble M. Synthesis, antioxidant evaluation, and quantitative structure-activity relationship studies of chalcones. Med Chem Res. 2011;20: 482-492.

[42] Herencia F, Ferrándiz ML, Ubeda A, et al. Novel anti-inflammatory chalcone derivatives inhibit the induction of nitric oxide synthase and cyclooxygenase- 2 in mouse peritoneal macrophages. FEBS Lett. 1999;453:129-134.

[43] Rojas J, Domínguez JN, Charris JE, et al. Synthesis and inhibitory activity of dimethylamino-chalcone derivatives on the induction of nitric oxide synthase. Eur J Med Chem. 2002;37:699-705. 